\title{
Dossiê
}

Partidos políticos, eleições e comportamento político-eleitoral no Brasil

\section{Emendas individuais e concentração de votos: uma análise exploratória ${ }^{1}$}

\author{
Lara Mesquita \\ Doutoranda em Ciência Política no IESP/UERJ e pesquisadora do NECI/USP \\ laramesquita@gmail.com \\ Graziele Silotto \\ Mestranda em Ciência Política no DCP/USP e pesquisadora do NECI/USP \\ grazielesilotto@gmail.com
}

Joyce Luz

Graduanda em Ciências Sociais USP e pesquisadora do NECI/USP

joheluz@gmail.com

Paulo Hubert

Mestre em Estatística e Pesquisador do NECI/USP

paulo.hubert@gmail.com

\begin{abstract}
Resumo: $O$ diagnóstico preponderante na literatura sobre a importância das emendas ao orçamento aponta para seu uso como moeda de troca eleitoral. Elas teriam como destino redutos eleitorais dos deputados com o objetivo de premiar e manter os eleitores que os apoiaram no momento da eleição. O intuito deste trabalho é averiguar se essas emendas de fato são usadas com este objetivo. Se essa hipótese estiver correta, espera-se encontrar maior alocação de emendas nos municípios em que o deputado concentra seus votos. Utilizando resultados eleitorais para deputados federais de todo o Brasil nas eleições entre 1994 e 2006 e a base de dados orçamentária, buscamos verificar se essa hipótese se confirma. Na tentativa de medir a importância que um determinado município tem para o resultado eleitoral de
\end{abstract}

1 Este trabalho foi desenvolvido no âmbito do projeto temático Instituições políticas, padrões de interação executivo-legislativo e capacidade governativa (CEBRAP/NECI), processo no 2011/08536-1, Fundação de Amparo à Pesquisa do Estado de São Paulo - FAPESP. As opiniões, hipóteses, conclusões ou recomendações expressas são de responsabilidade dos autores e não necessariamente refletem a visão da FAPESP. Uma versão preliminar deste trabalho foi apresentada no IX Encontro da Associação Brasileira de Ciência Política, realizado em Brasília, em agosto 2014. Os autores agradecem os comentários do Grupo de Estudos Eleitorais do Núcleo de Estudos Comparados Internacionais (NECI-USP) e do parecerista anônimo da revista Teoria e Pesquisa. 
um deputado federal, testamos três indicadores diferentes que relacionam a quantidade e proporção de votos e cruzamos com as informações sobre alocação de emendas no período. Embora os resultados pareçam corroborar as teses predominantes na literatura política brasileira, uma análise mais cuidadosa, que vá além da simples descrição dos dados, aponta que a relação entre concentração de votos e alocação de emendas é mais fraca do que se imaginava.

Palavras-chave: Concentração de votos; Conexão eleitoral; Distributivismo; Emendas individuais.

Abstract: The literature's main diagnosis about individual amendments proposed by federal deputies to the budget relates it with distributives' politics by means of the electoral connection: politicians who deliver concentrated benefits - pork barrel politics - to particular constituencies in exchange of its voting. Using the electoral outcomes for federal deputies in Brazil between 1994 and 2006 and the budgetary data set, this paper intends to test the electoral connection hypothesis. If the electoral connection thesis is correct, we expect to find a higher allocation of the budget amendment in the municipalities where the candidate's votes are concentrated, his constituency. In order to measure the importance of a municipality for the electoral results of a federal deputy, we tested three different indexes that relate the amount of resources proposed through the budget amendments and proportion of votes associated with the budget allocation information. Even though the results seem to confirm the prevailing thesis of the literature, a more systematic analysis that goes beyond the descriptive data indicates that the relation between the concentration of votes and the allocation of the budget amendment is weaker than it was envisioned.

Key words: Concentration of votes; Electoral connection; Distributives politics; Budget amendment.

\section{Introdução}

Tanto o senso comum como a literatura tratam as emendas individuais ao orçamento como moedas de troca entre parlamentares e eleitores. Onde há voto, haveria também emendas dos parlamentares mais bem votados.

Estadão: O senhor apresentou emendas para cidades onde foi o mais votado. Isso teve peso?

Gastão Vieira (PMDB): É evidente. Fui o deputado mais votado do Maranhão em função do meu trabalho. (...) Você trabalha, a população pede, fica satisfeita e o resultado vem. Essa é a vida de um parlamentar. Não há outra razão para alguém ser parlamentar a não ser beneficiar a população onde ele tem a sua base política, para que essa população o mantenha como seu bom representante (Gastão Vieira, em entrevista ao Estadão, 15 set. 2011). 
No entanto, cabe questionar se tal fato encontra base na empiria. Esse é o propósito deste trabalho. Deputados de fato "premiam" com emendas os municípios nos quais recebem mais votos? Os resultados não são conclusivos nesse sentido: embora haja indícios de que o resultado eleitoral tenha alguma influência na alocação das emendas, não é possível afirmar que se trata do fator dominante no processo de decisão dos deputados.

Nas seções seguintes faremos um balanço da literatura sobre o tema, depois apresentaremos os dados e posteriormente metodologias e resultados. Por fim, este trabalho se encerra com uma conclusão e apontamentos para os próximos passos.

\section{Emendas individuais, "moeda de troca" e sucesso eleitoral?}

Tendo em vista os arranjos adotados após a Constituição de 1988, o diagnóstico sobre o Brasil é o de que a política institucional brasileira favoreceria uma presidência forte e plebiscitária e um Legislativo conservador. O Congresso seria o locus ideal da indisciplina e da falta de coesão por parte dos parlamentares. A permissividade das regras eleitorais, como a representação proporcional de lista aberta, produziria competição intrapartidária, criando incentivos ao comportamento individualista dos políticos, cujo objetivo seria manter seus cargos políticos e conquistar a reeleição. A condição para o sucesso seria, portanto, a conquista de bases eleitorais, que se daria mediante o uso de políticas distributivistas do tipo pork barrel.

A consequência do cenário relatado acima seria um sistema partidário fragmentado e constituído por agentes coletivamente fracos. Os parlamentares se comportariam de maneira pouco coesa e indisciplinada, orientados mais pela lógica do voto pessoal (Carrey \& Shugart, 1995) e por estratégias localistas do que pela lógica da disciplina partidária. A fragmentação partidária existente, por sua vez, dificultaria a formação de coalizões de apoio estáveis, deixando o Executivo sem o apoio de uma maioria parlamentar para aprovar sua agenda. Tal fato levaria o país, naturalmente, a uma crise de governabilidade.

No entanto, de modo a evitar essa situação extrema, o Executivo, mediante a oferta de cargos burocráticos e de recursos orçamentários, negociaria com os parlamentares em troca de apoio político. E aqui cabe ressaltar que, embora a oferta de cargos 
burocráticos seja uma estratégia comum de barganha, ela não seria suficiente para garantir o apoio dos parlamentares, uma vez que sob a ótica do deputado essa prática não contribuiria para o seu sucesso eleitoral - seu sumo objetivo. Seria por esse motivo que o Executivo, com vista à obtenção de apoio político, concederia também emendas individuais orçamentárias aos parlamentares. Essas emendas possibilitariam aos candidatos/ parlamentares a implementação de políticas distributivistas, beneficiando seu eleitorado que, em troca, Ihe concederia o voto, promovendo a manutenção e obtenção de cargos políticos (Pereira \& Mueller, 2002).

A premissa de fundo da argumentação exposta acima é a de que políticos seriam atores racionais cuja atuação parlamentar orientar-se-ia exclusivamente pela lógica office-seeking, ou seja, os atores se interessariam somente pela continuidade dos seus mandatos e a reeleição (Mayhew, 1974).

Indo um pouco mais além, tal linha argumentativa articularia as arenas eleitoral e legislativa através do conceito de conexão eleitoral. Neste cenário, a utilização de recursos orçamentários através das emendas individuais para destinar verbas para suas bases eleitorais seria a estratégia predominante dos políticos, que teriam o intuito de que estes benefícios fidelizassem seus eleitores além de serem convertidos em futuros votos. O pork barrel seria, portanto, a chave no funcionamento do sistema político brasileiro e explicaria tanto a atuação dos parlamentares no Congresso como sua relação com os eleitores, notadamente fisiologista.

Ames $(1995,2003)$ é um dos principais autores a assumir o predomínio da conexão eleitoral e do voto pessoal como pilares do funcionamento do sistema político brasileiro. Segundo o autor, embora os votos sejam buscados oficialmente em todo o Estado, muitos candidatos a deputado federal focariam suas campanhas em regiões geograficamente delimitadas. Estas regiões constituiriam os chamados distritos informais, ou redutos eleitorais. Seriam formados vínculos de caráter personalistas entre eleito e eleitor, de maneira a beneficiar as demandas daquele eleitorado que, em troca, dera seu voto ao candidato que o beneficiou. Daí o argumento de que "a política brasileira favorece a provisão de benefícios locais, geograficamente separáveis" (Ames, 2001:68).

Em uma tentativa de analisar os principais determinantes da reeleição para o cargo de deputado federal, Pereira e Rennó (2001) afirmam que os parlamentares brasileiros, como principal estratégia para reeleição, concentrar-se-iam em distribuir benefícios 
para as suas bases eleitorais, tendo como principal esforço a negociação da liberação de recursos - traduzidos em emendas individuais. Nas palavras dos autores:

[...] diante das opções e recursos disponibilizados durante seus mandatos, a distribuição de benefícios locais proporciona muito mais retornos eleitorais do que as atividades legislativas dentro da Câmara ou as posições de voto assumidas em relação a uma determinada política (Pereira \& Rennó, 2001:12).

Embora a argumentação central estabelecida acima seja a de que o arranjo institucional brasileiro favoreceria o comportamento individualista dos parlamentares, que agiriam somente em busca de recursos para se reelegerem, há analistas (Diniz, 2005; Figueiredo \& Limongi, 1999, 2002, 2009; Freitas, 2010) que defendem que o sistema institucional brasileiro funcionaria devido à concentração de poderes do presidente e dos líderes partidários. Nesta outra vertente, as emendas individuais ao orçamento não seriam essenciais na garantia do funcionamento do sistema presidencialista. E sendo assim, o comportamento coeso e disciplinado dos parlamentares seria resultado da centralidade dos partidos dentro do Legislativo e não da execução de emendas individuais ao orçamento como "moeda de troca" (Figueiredo \& Limongi, 2002).

Dado o controle que o Executivo detém no processo orçamentário, a lógica das emendas individuais seria menos localista e mais ligada às preferências e programas priorizados pelo governo (Figueiredo \& Limongi, 2005). O que o estudo sobre a alocação das emendas dos parlamentares evidencia é que cada parlamentar não possui uma estratégica única para garantir o sucesso eleitoral. Sendo que muitas dessas estratégias estão, na maioria das vezes, mais ligadas à trajetória política individual de cada deputado do que à localidade para onde destinam suas emendas. Além disso, em muitos municípios alvos das emendas individuais a concentração de votos dos parlamentares chega a ser pequena e até mesmo irrelevante (Mesquita, 2008).

Nesta mesma direção e mais próximo dos objetivos deste trabalho, Silva (2009) procurou demonstrar que as escolhas das cidades que receberão recursos orçamentários por parte dos deputados federais de São Paulo não estariam somente relacionadas com a concentração de votos desses candidatos em determinados municípios. Mediante análises que envolveram tanto a quantidade de emendas individuais quanto seus respectivos valores, o autor chegou à conclusão: 
As cidades não são tratadas de maneira equivalente por todos os deputados. Independentemente de quais são os deputados que receberam muitos votos em cada uma dessas cidades, estes não se preocuparam em atender a população destas cidades com o mesmo número de emendas. Por outro lado, os deputados entendem que a proposição de emendas atenderá de forma diferente as populações (Silva, 2009:123).

Segundo os resultados (Silva, 2009), os deputados federais paulistas utilizariam os recursos das emendas individuais não com o objetivo de concentrar suas votações futuras, mas sim com a finalidade contrária, ou seja, de desconcentrar seus resultados eleitorais. Ou seja, menos com objetivo de premiar votos recebidos do que com o objetivo de conquistar novos votos, em regiões diferentes daquelas em que o deputado já foi votado no passado.

Apesar dessa outra perspectiva do funcionamento do sistema político brasileiro, os argumentos sobre a relação clientelista dos políticos com seu eleitorado e a importância do reduto eleitoral como meio de sobrevivência política se mantêm predominantes na literatura política sobre o Brasil (Ames, 2003; Lamounier, 1992; Mainwaring, 1991; Pereira \& Mueller, 2002; Pereira \& Renno, 2001, 2007) e no senso comum. Dessa forma, cabe questionar: Os deputados federais brasileiros tentariam, mediante ao uso de recursos orçamentários, premiar aqueles municípios cuja votação foi importante para seu sucesso eleitoral?

Se deputados premiam suas "bases", então como esses deputados conseguiriam medir a importância de um município em seus resultados eleitorais para posteriormente premiá-los com a apresentação de emendas individuais? Esses deputados usariam mesmo a concentração de votos como estratégia para distribuir seus recursos? Essas são as questões que serão abordadas ao longo deste trabalho.

Embora Silva (2009) já tenha questionado a premissa de que deputados premiam suas bases eleitorais com recursos orçamentários e tenha encontrado que há outras motivações no destino de emendas individuais, sua pesquisa ficou restrita aos deputados paulistas. Este trabalho, ao analisar quatro eleições e todo o universo dos deputados eleitos, pretende avançar e apresentar um panorama mais fiel ao cenário brasileiro como um todo. 


\section{Descrição dos dados}

Este trabalho analisa os dados para quatro eleições nacionais: 1994, 1998, 2002 e $2006^{2}$ e os respectivos anos orçamentários que cobrem essas legislaturas que vão desde 1996 até 2011. ${ }^{3}$ Assim, para cada ano eleitoral analisado, têm-se os seus respectivos quatro anos orçamentários. O trabalho ainda engloba nas análises todos os estados brasileiros e os respectivos deputados que propuseram emendas durante o período exposto acima. Cabe ressaltar que serão utilizados para análise os dados de orçamento aprovados, ou seja, os valores aprovados perante a Comissão Mista do Orçamento (CMO). ${ }^{4}$

A tabela 1 mostra, de acordo com a legislatura, o total de parlamentares que propuseram emendas destinadas a municípios ${ }^{5}$ e quantos desses parlamentares eram titulares ou suplentes.

Tabela 1: Quantidade de parlamentares que propuseram emendas por legislatura

\begin{tabular}{cccc}
\hline Legislatura & Titulares & Suplentes & Total \\
\hline 1995 & 496 & 97 & 593 \\
\hline 1999 & 502 & 77 & 579 \\
\hline 2003 & 485 & 71 & 556 \\
\hline 2007 & 495 & 64 & 559
\end{tabular}

Fonte: Elaboração própria a partir do Banco de Dados Orçamento-CEBRAP e Dados Eleitorais-Centro de Estudos da Metrópole.

No tocante às emendas individuais entre 1996 e 2007, a quantidade máxima de emendas para cada deputado federal é de 20 por ano. Esse número, no entanto, aumenta para 25 por ano em 2008. Já no que diz respeito aos valores, em 1996 o valor

2 As eleições de 2010 não serão incluídas porque os dados orçamentários completos referentes à legislatura 540, iniciada em $1^{\circ}$ de fevereiro de 2011, ainda não estão disponíveis.

3 Aqui cabe uma explicação a respeito do uso dos anos orçamentários e sua correspondência com os anos eleitorais. Um ano orçamentário representa sempre o ano de sua execução. Contudo, de acordo com a Constituição Brasileira, a Lei Orçamentária Anual (LOA) deve ser sempre planejada e aprovada um ano antes de sua execução. Assim temos, por exemplo, que o ano orçamentário de 2011 começou a ser planejado em 2010 pelos deputados que foram eleitos ainda em 2006, uma vez que os deputados eleitos em 2010 só assumiram seu mandado em 2011 e foram os responsáveis por planejar o orçamento referente ao ano de 2012.

4 A utilização dos dados de orçamento aprovados se dá porque estes são os dados que a Câmara dos Deputados disponibiliza. Estes dados se referem aos valores aprovados pela CMO tendo em vista os projetos propostos pelos deputados. Há que se ressaltar que estes valores diferem dos valores de fato executados, ou seja, os valores que de fato chegaram aos municípios ou estados.

5 Foram retiradas das análises as emendas individuais propostas para Estados e para municípios que não pertencem ao estado em que o deputado federal foi eleito. 
geral máximo era de 5,9 milhões ${ }^{6}$ por deputado. Esse valor diminui entre 1995 e 2005, e em 2006 volta a subir, até atingir 14,4 milhões no último ano de análise, em 2011, conforme a tabela 2 .

Tabela 2 - Quantidades e valores das emendas individuais por deputado federal

\begin{tabular}{cccc}
\hline Ano Loa & $\begin{array}{c}\text { Quantidade de emendas } \\
\text { individuais possíveis }\end{array}$ & Valor máximo possível & $\begin{array}{c}\text { Valor máximo possível } \\
\text { deflacionado (dez./2012) }\end{array}$ \\
\hline 1996 & 20 & 1,5 milhão & 6 milhões \\
\hline 1997 & 20 & 1,5 milhão & 5,5 milhões \\
\hline 1998 & 20 & 1,5 milhão & 5,3 milhões \\
\hline 1999 & 20 & 1,5 milhão & 4,7 milhões \\
\hline 2000 & 20 & 1,5 milhão & 4,1 milhões \\
\hline 2001 & 20 & 2 milhões & 5 milhões \\
\hline 2002 & 20 & 2 Milhões & 4,3 milhões \\
\hline 2003 & 20 & 2 milhões & 3,7 milhões \\
\hline 2004 & 20 & 2,5 milhões & 4,1 milhões \\
\hline 2005 & 20 & 3,5 milhões & 5,4 milhões \\
\hline 2006 & 20 & 5 milhões & 7,5 milhões \\
\hline 2007 & 20 & 6 milhões & 8,5 milhões \\
\hline 2008 & 25 & 7 milhões & 9,1 milhões \\
\hline 2009 & 25 & 8 milhões & 10,1 milhões \\
\hline 2010 & 25 & 12,5 milhões & 14 milhões \\
\hline 2011 & 25 & & \\
\hline
\end{tabular}

Fonte: Elaboração própria a partir dos pareceres preliminares da LOA

Tendo isso em vista, é preciso ressaltar que deputados federais têm que lidar com uma quantidade de emendas individuais pequena para, em tese, presentear seu eleitorado. Ainda que alguns estados tenham um baixo número de municípios, em estados como São Paulo e Minas Gerais, por exemplo, o número de 25 emendas representa apenas 0,03\% e 0,02\% dos municípios, respectivamente. No entanto, se deputados fazem uso apenas de recursos orçamentários para premiar suas bases eleitorais, como podem fazê-lo satisfatoriamente uma vez que o número de emendas individuais possíveis é tão baixo?

6 Todos os valores das emendas individuais tratados neste trabalho foram corrigidos de acordo com a inflação até dezembro de 2012. 
Cabe ainda observar quantos municípios são premiados pelos deputados. Tomando como critério o município que recebeu no mínimo 1 emenda individual por ano, o gráfico 1 mostra, por legislatura, quantos municípios de fato foram beneficiados com alguma emenda individual. Há que se notar que a tendência geral é de queda na quantidade de municípios beneficiados a cada ano.

\section{Gráfico 1: Quantidade de municípios que recebem emendas por legislatura}

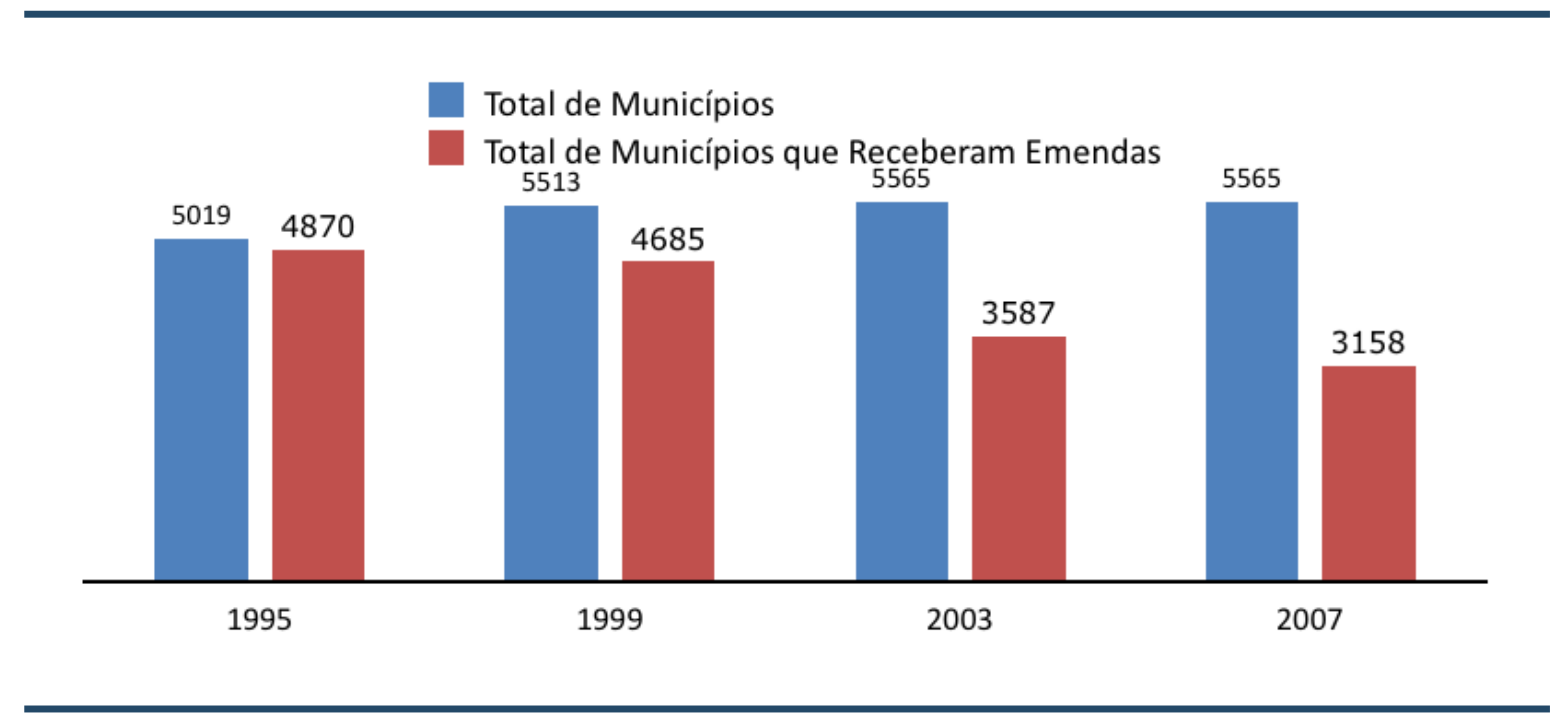

O dado que merece destaque aqui é que, a partir da legislatura de 2003, há uma queda significativa no total de municípios que recebem emendas: a diminuição é de cerca de 25\% em relação à legislatura anterior. Tal achado pode ser explicado pelo fato de que, também a partir de 2003, as emendas cujo alvo eram os municípios terem mudado de destino: se antes as cidades eram as mais beneficiadas financeiramente, a partir de 2003 são as unidades federativas que passam a ter preferência nas prioridades dos deputados federais, conforme evidencia o gráfico 2 abaixo. 


\section{Gráfico 2 - Destino das emendas individuais em valores}

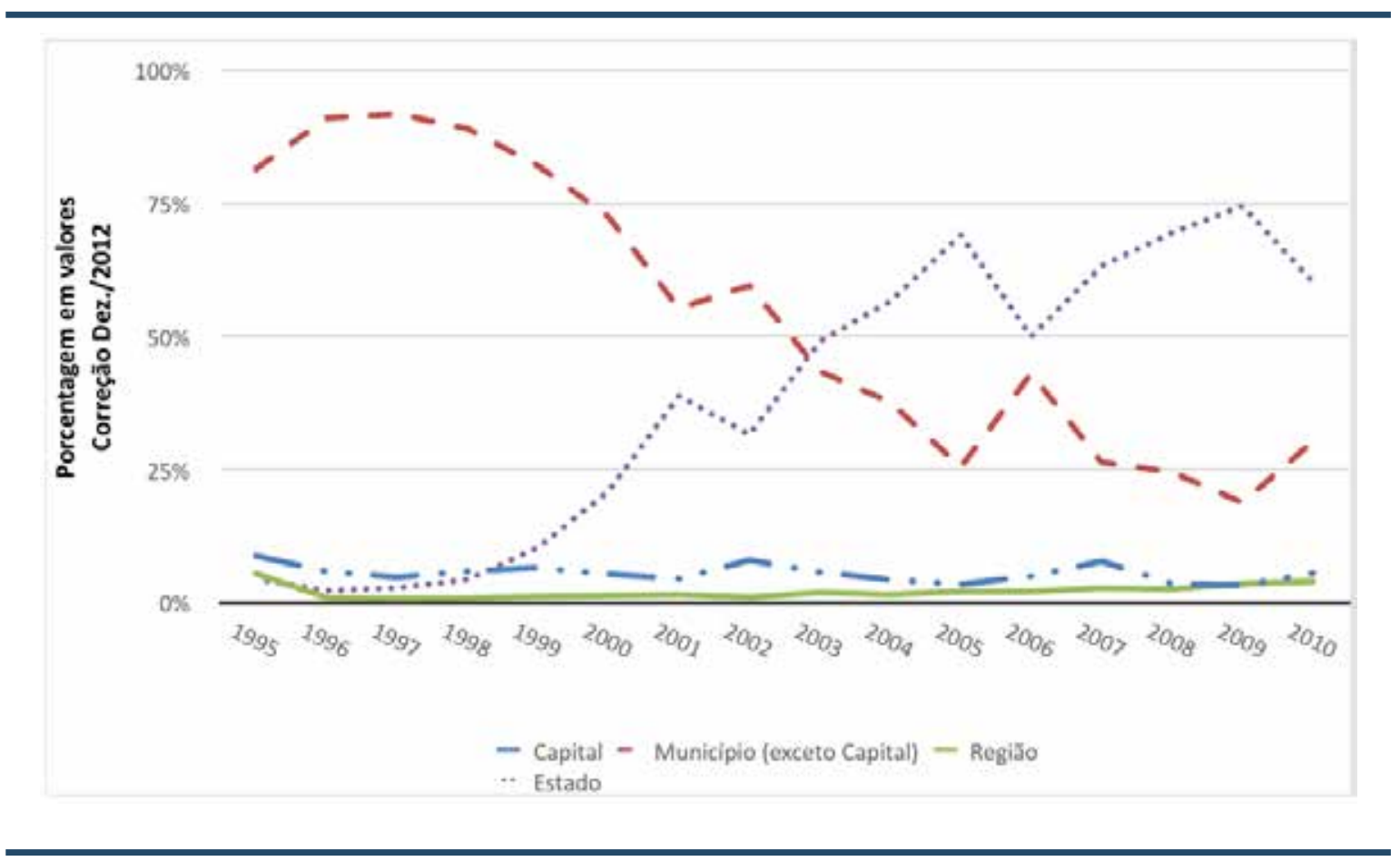

Se, na verdade, são os estados, e não os municípios, os mais beneficiados financeiramente pelos deputados via emendas individuais, então o argumento da conexão eleitoral articulada pelo voto pessoal de cunho clientelista como base do funcionamento do sistema político brasileiro parece estar posto em cheque. Se deputados de fato premiam seus distritos informais, qual a razão de o destino das emendas ser prioritariamente os estados e não os municípios?

\section{Importância dos municípios e sucesso eleitoral}

Ainda que a alocação majoritária das emendas nos estados, sem uma localização definida, por si só questione a estratégia de utilização das emendas como meio de premiar os eleitores que votaram em um dado deputado, é fundamental entendermos melhor esse fenômeno. Afinal, como argumenta Mesquita (2008), os deputados têm diversos interesses com as alocações das emendas, e não podemos descartar que o objetivo de "retribuir" os votos recebidos seja um deles, sem antes conhecer como se dá a alocação das emendas individuais. 
A primeira pergunta que se coloca quando nos perguntamos se as emendas são usadas como moeda de troca para retribuir votos recebidos na última eleição é: Os deputados alocam emendas apenas em cidades onde receberam votos, há alguma variação nesse comportamento?

A cada legislatura, em média, mais de 300 cidades onde os deputados não receberam nem um voto sequer recebem emendas. Dito de outra forma, há mais de 300 casos em cada legislatura em que um deputado aloca ao menos uma de suas emendas em uma cidade onde não recebeu votos.

Por outro lado, como mostrado anteriormente pelo gráfico 1, nas duas últimas legislaturas mais de 2.000 municípios não foram agraciados com nenhuma emenda. Embora não seja a regra, não raro os deputados abrem mão de alocar emendas em localidades que tiveram algum voto em detrimento de outras em que não foram votados.

As tabelas 4 e 5 abaixo foram feitas tendo como unidade o par deputado X município, para cada legislação. Elas nos mostram que há sim um efeito de alocação das emendas em favor das cidades em que os parlamentares receberam votos. Aqui não distinguimos a quantidade de votos, e sim apenas se os deputados receberam ou não votos no município. Também as emendas não são distintas, apenas consideramos se em algum dos anos da legislatura o deputado apresentou pelo menos uma emenda para aquele município. Por exemplo, no caso do Amapá, que elege 8 deputados e possui 16 municípios, o universo possível é 128 pares deputado X município a cada legislatura. Como são 4 as legislaturas incluídas nessa análise, o Amapá responde por 512 linhas na planilha que originou os quadros abaixo.

As tabelas 4 e 5 são tabelas simples 2X2 que nos mostram a distribuição das emendas (sim ou não apresentou emenda ao orçamento com destino à localidade, sim ou não teve votos na localidade).

A primeira linha de ambas as tabelas é composta pelo conjunto de municípios que não receberam emendas, sendo que na primeira coluna temos os municípios que o deputado não recebeu votos nem apresentou emendas e na segunda coluna os municípios em que cada deputado teve votos e não apresentou emenda. 
A segunda linha é composta pelo conjunto de municípios em que receberam emendas, sendo que na primeira coluna temos o subconjunto que não há recebimento de voto e na segunda em que há recebimento de votos.

Na tabela 4 são apresentadas a distribuição observada e (entre parênteses) a distribuição esperada para a tabela.

Tabela 4 - Distribuição conjunta observada e esperada

\begin{tabular}{lccc}
\hline & \multicolumn{2}{c}{ Votos } \\
\hline \multirow{3}{*}{ Emendas } & \multicolumn{3}{c}{ Não } \\
& & Sim & observada (esperada) \\
\cline { 2 - 4 } & \multirow{2}{*}{ Não } & $26,65 \%$ & $68,09 \%$ \\
& & $(25.43 \%)$ & $(69.31 \%)$ \\
\cline { 2 - 4 } & \multirow{2}{*}{$\operatorname{Sim}$} & $0,19 \%$ & $5,06 \%$ \\
& & $(1.41 \%)$ & $(3.84 \%)$ \\
\hline
\end{tabular}

A tabela 5 apresenta a distribuição dos resíduos padronizados do teste de Qui-Quadrado.

Tabela 5 - Teste de Qui-Quadrado - Resíduos padronizados

\begin{tabular}{llcc}
\hline & \multicolumn{3}{c}{ Votos } \\
\hline \multirow{3}{*}{ Emendas } & & Não & Sim \\
\cline { 2 - 4 } & Não & 447,98 & 164,37 \\
\cline { 2 - 4 } & Sim & 8079,70 & 2964,64 \\
\hline
\end{tabular}

O teste de Qui-quadrado para esta tabela resultou numa estatística de valor 11656,69, com p-valor associado igual a 0 - que comprova a significância desse viés.

Há diferença, portanto, entre os resultados observados e esperados, sendo a diferença mais significativa a que diz respeito ao universo dos municípios que recebem emendas. Enquanto a distribuição observada em relação às localidades sem votos é significativamente inferior à esperada, ela é significativamente superior nos municípios 
em que se recebem votos. Ou seja, há um viés positivo em alocar emendas em cidades onde se recebem votos.

Em resumo o que sabemos até o momento é que sim, os municípios em que os deputados recebem votos recebem mais emendas do que municípios em que os deputados não recebem votos. Ainda assim municípios em que os deputados não recebem votos recebem emendas. Há diferença de valor entre as emendas alocadas nesses dois tipos de municípios?

No gráfico 3 a largura da caixa do boxplot indica a quantidade de casos em cada um dos tipos de município, enquanto a linha preta no centro da caixa indica a mediana.

\section{Gráfico - Proporção do valor das emendas nos municípios com e sem votos} (1994-2006)

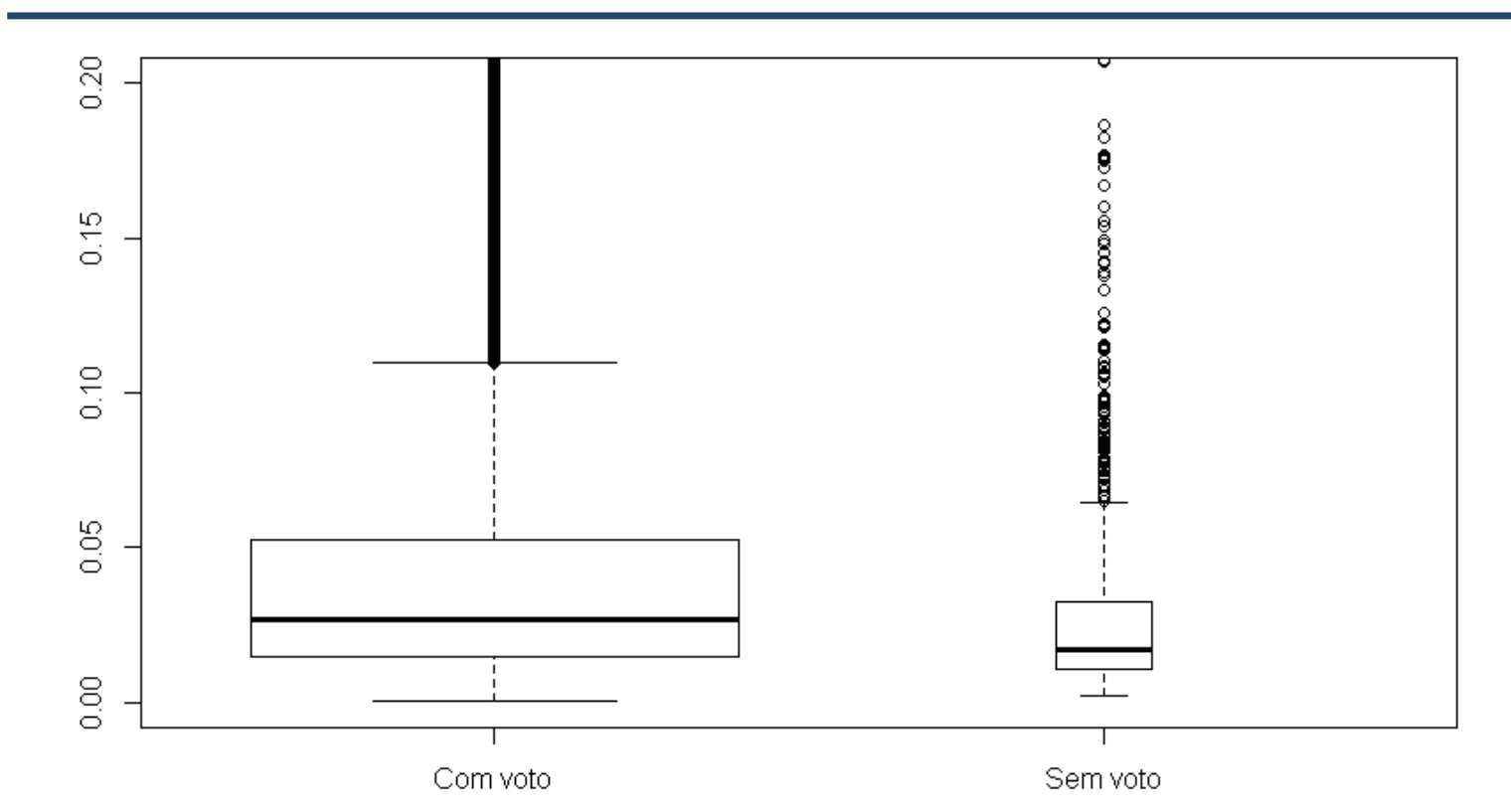

Há diferença entre os valores alocados nos municípios em que os deputados recebem votos e aqueles em que eles não recebem, embora essa diferença seja pequena e com muita variação.

A partir desse ponto, trabalharemos apenas com a unidade municípios $X$ deputados que receberam emendas individuais do orçamento. Uma vez que sabemos que há um viés em favor da alocação dos recursos proveniente das emendas individuais nos 
municípios em que os deputados recebem votos, e que a despeito da grande variação nos valores essas localidades recebem mais recursos do que aquelas em que os deputados não recebem votos, a pergunta que se coloca é: Os parlamentares privilegiam as cidades mais importantes eleitoralmente para eles em detrimento das outras cidades?

Esse questionamento é importante pois, como vimos na seção anterior, é limitado tanto o valor que os deputados podem apresentar em emendas quanto o número de emendas que podem ser apresentadas, o que por sua vez restringe o número de municipalidades que podem receber emendas de cada um dos deputados.

Mas como definir quais são os municípios/cidades importantes eleitoralmente para cada deputado? Será que a localidade em que ele recebe a sua maior votação é a mais importante, independentemente do peso eleitoral que essa cidade tenha no estado, ou há uma ponderação quanto ao peso do deputado na cidade além do número de votos dele, que tem como origem esse município?

Como essa não é uma questão simples de se responder e provavelmente não apresenta uma resposta única, escolhemos distintas maneiras de definir a importância eleitoral dos municípios para os deputados e analisamos a alocação das emendas individuais para todas elas.

A primeira escolha e mais óbvia é analisar a distribuição das emendas apresentadas pela proporção de votos dos deputados em cada município, ou seja, o quanto cada município contribuiu com o total de votos que o deputado recebeu.

É o que podemos ver no gráfico 4 a seguir,7 que considera em conjunto as legislaturas 1995, 1999, 2003 e 2007.

7 Os valores das emendas estão apresentados nos gráficos em \% sobre o valor total das emendas individuais destinadas a municípios por uma questão de facilitação da visualização. Como os valores variam de alguns milhares de reais a alguns milhões, os gráficos ficariam de difícil compreensão se optássemos pelos valores em absolutos e não pela proporção dos valores. 
Gráfico 4 - Proporção dos valores das emendas pelo \% de votos do candidato no município

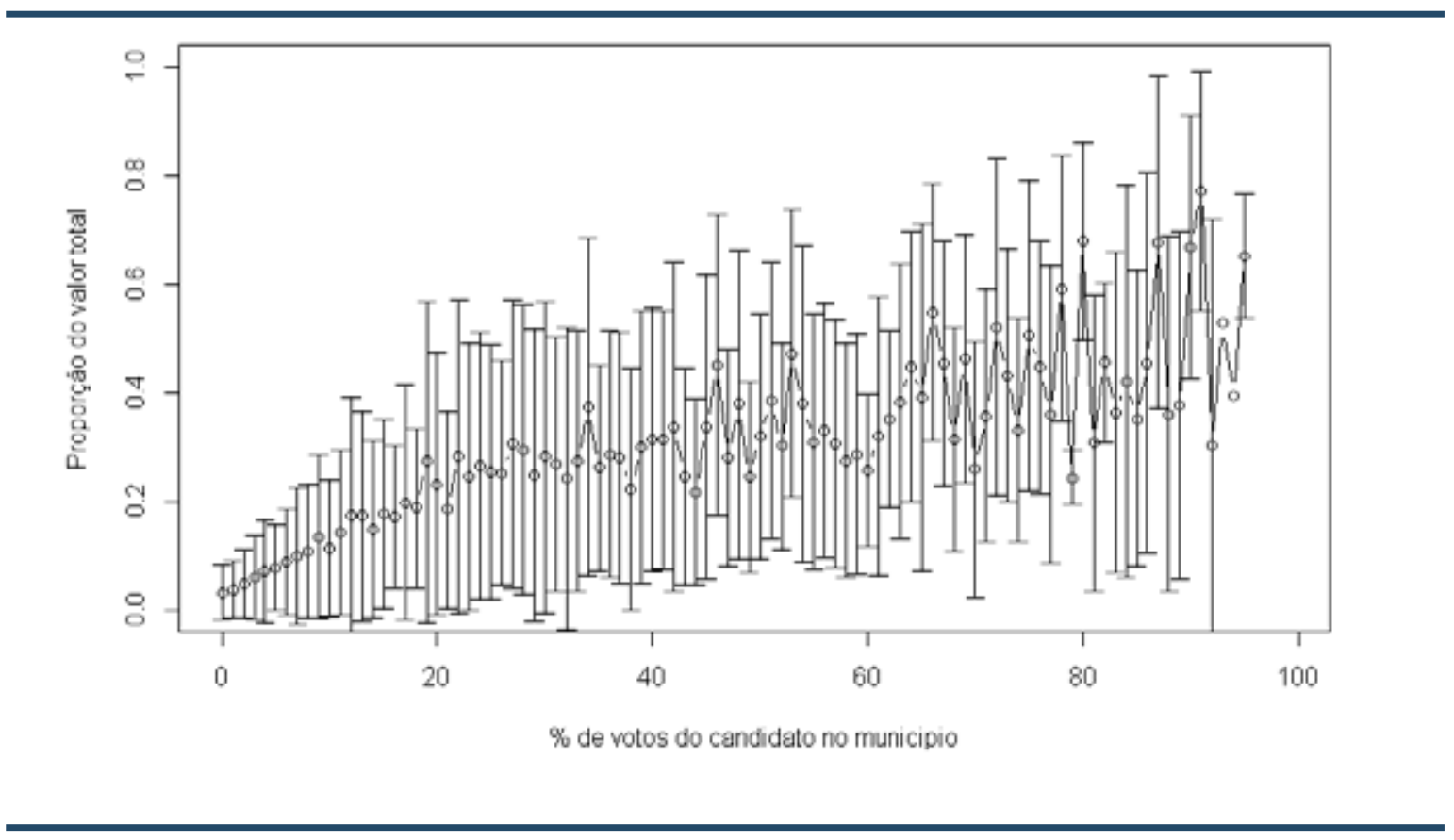

Os marcadores indicam a proporção média do valor total das emendas que têm por destino municípios, conforme o percentual do total de votos que cada deputado teve em dado município. As barras indicam um desvio padrão para mais e para menos. Há um aumento sistemático no valor das emendas entre as cidades com distribuição entre zero e 20\%, mas, a partir desse ponto, o que se verifica é um movimento errático, com desvios muito grandes.

Optamos por apresentar o gráfico desta forma resumida, pois a nuvem de pontos e o mapa de calor (scatterplot e heatmap, gráficos 4.1 e 4.2 abaixo) não permitem conclusões mais profundas. Podemos ver apenas que existe uma concentração alta dos pontos no canto inferior direito dos gráficos. 
Gráfico 4.1 - scatterplot para a proporção de valores das emendas e a \% de votos do candidato no município

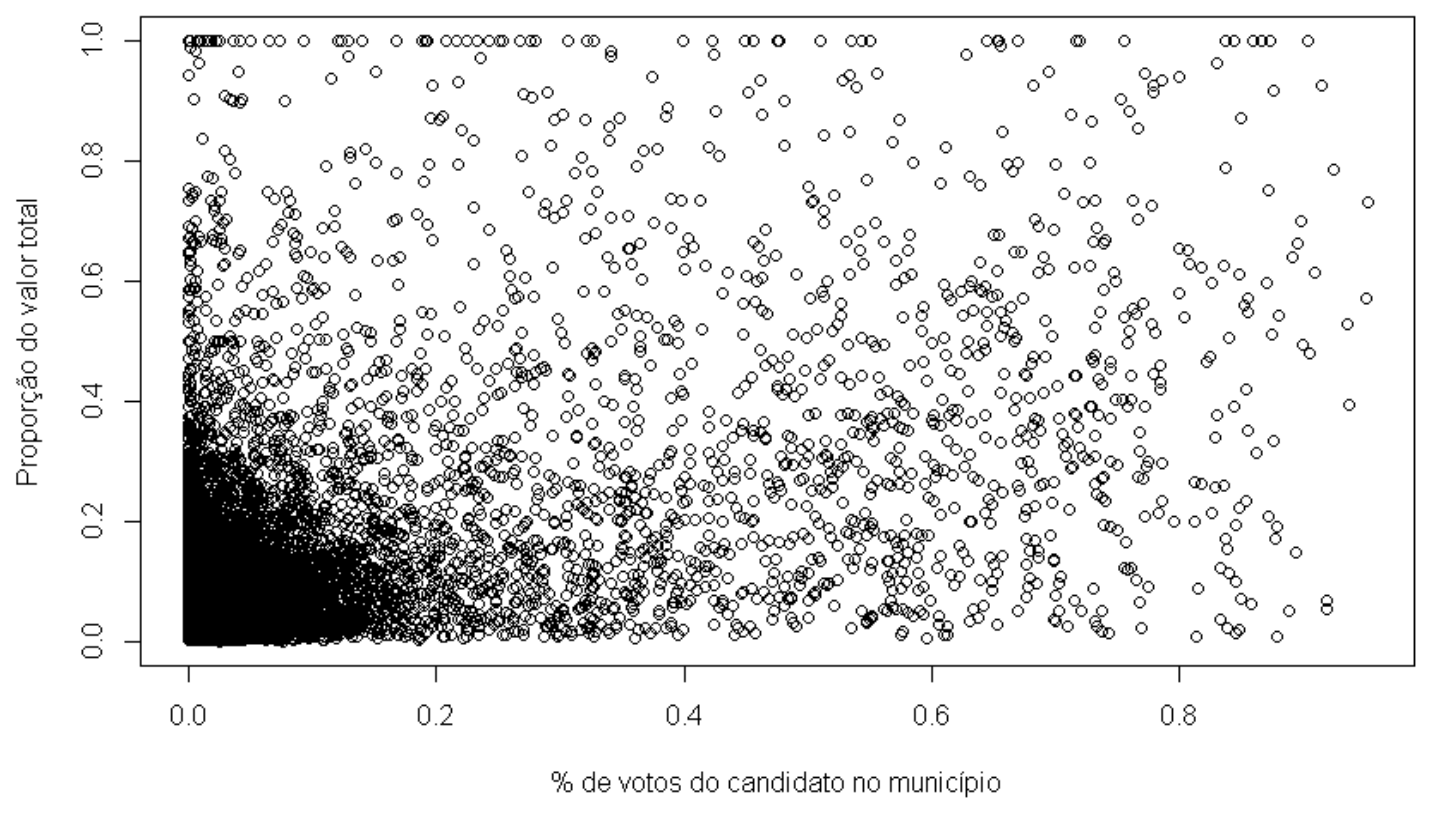

Gráfico 4.2 - heatmap para a proporção de valores das emendas e a \% de votos do candidato no município

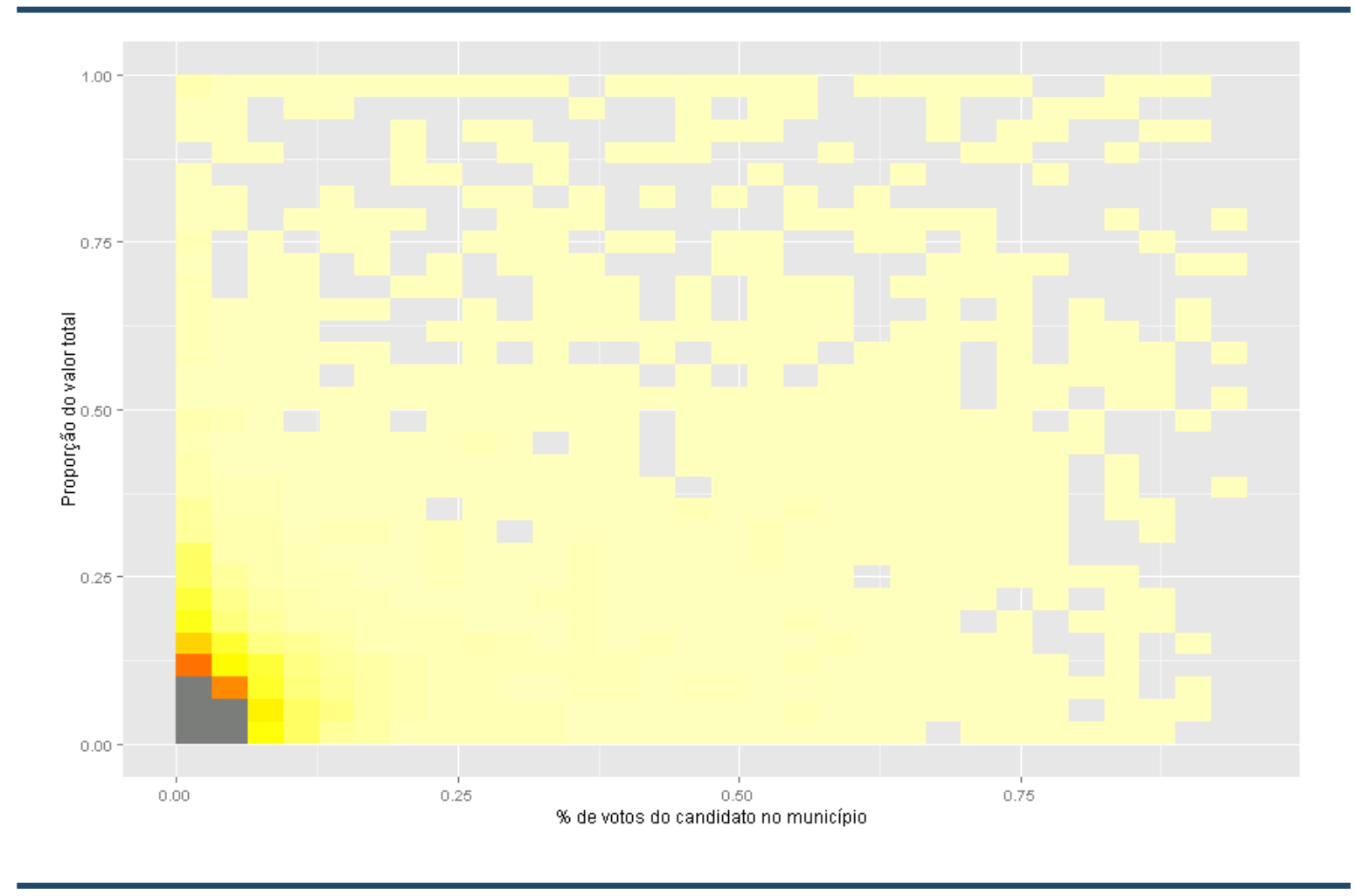


Para facilitar ainda mais a interpretação desses dados, agrupamos o percentual de votos em faixas de 10\%, como podemos ver no gráfico abaixo. ${ }^{8}$ Assim como no gráfico 3 apresentado anteriormente, quanto mais larga a caixa maior o número de casos registrado no intervalo designado.

Devido à limitação de espaço desse artigo, optamos por apresentar os resultados agrupados para todas as legislaturas, o que não se mostrou um problema, uma vez que não há variação do comportamento entre as legislaturas. ${ }^{9}$

Gráfico 5 - Proporção dos valores das emendas por \% de votos do candidato no município

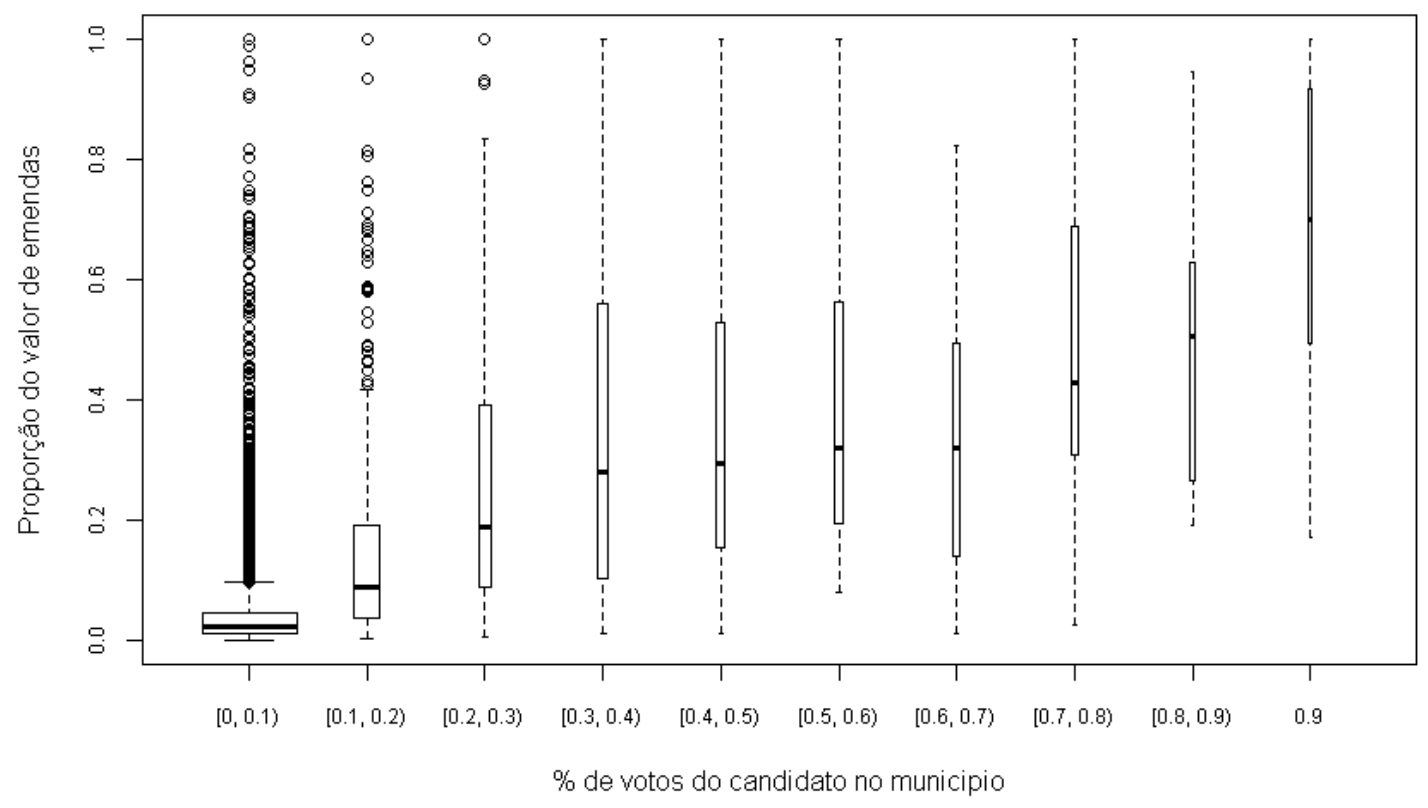

O maior número de casos se concentra nas faixas de 0 a 20\% de votos do candidato nos municípios, os dois primeiros boxplots da sequência. Isso significa que a maioria dos deputados recebe até 20\% dos seus votos em um único município. Em toda a série histórica são raros os casos em que um deputado eleito recebe um grande percentual dos seus votos em uma única localidade. Na verdade, os casos de 100\% se referem

8 Para tanto, só foi considerada a primeira casa decimal, assim todos os valores entre 0 e 0,099 (ou 9,99\%) estão na primeira faixa, todos entre 0,1 e 0,199 (ou entre 10\% e 19,99\%) na segunda faixa e assim por diante.

9 Os gráficos por legislaturas estão disponíveis mediante solicitação. 
todos aos deputados eleitos pelo Distrito Federal, uma vez que Brasília se comporta como um estado formado por uma única cidade.

A tendência é a mesma para todas as legislaturas também quando observadas separadamente: é possível verificar um aumento sistemático na média da proporção do valor das emendas, conforme aumenta a proporção dos votos do candidato no município. A correlação linear de Pearson entre as duas variáveis é 0.57, aproximadamente, e uma regressão linear simples mostra um coeficiente de 0.60 para a proporção de votos, com $R^{2}$ de 0.32 .

Aqui cabe uma observação: o objetivo principal deste trabalho é exploratório. 0 resultado de análises de regressão é incluído apenas com o intuito de resumir de forma numérica as relações entre as quantidades analisadas. Uma análise inferencial mais profunda teria necessariamente que considerar outros possíveis fatores além do desempenho eleitoral. Análises desse tipo farão parte do desenvolvimento futuro desta pesquisa.

O passo seguinte é ver se, ao invés de premiar localidades em que recebem maiores proporções de votos, os parlamentares premiam localidades em que concentram votos. Como medida de concentração, utilizaremos o Quociente Locacional (QL) proposto por Silva (2009) e Silva e Davidian (2013).

O QL mensura o quão distante de uma distribuição ideal está o desempenho do candidato em uma determinada localidade. Ou seja, se uma dada municipalidade responde por 10\% dos votos do Estado, a distribuição ideal de um dado candidato seria a de que recebesse 10\% de seus votos nessa localidade. Quanto maior o valor do indicador mais concentrada, ou distante da distribuição ideal, é a distribuição dos votos de um dado candidato.

A fórmula para o cálculo do índice é a que se segue: $Q L=(V i, m / V i) /(V m / V t)$ onde $\mathrm{Vi}, \mathrm{m}=$ Votos do candidato i no município $\mathrm{m}$; $\mathrm{Vi}=$ Total de votos do candidato i no distrito; $\vee m=$ Total de votos do município $m$; e Vt = Total de votos no distrito $t$.

Para facilitar a visualização, os QLs foram agrupados em faixas de valores.

Mais uma vez, devido à limitação de espaço e à homogeneidade do comportamento dos dados em todas as legislaturas, os resultados serão apresentados em um único gráfico, desta feita representado pela última legislatura, iniciada em 2007 e que se refere aos resultados eleitorais de 2006. Optaremos de agora em diante por apresentar os gráficos 
apenas de forma categorizada, uma vez que (conforme observado nos gráficos 4.1 e 4.2) a nuvem de pontos dificulta a visualização das relações que queremos analisar.

Gráfico 6 - Proporção de alocação das emendas por faixa QL. Legislatura 2007

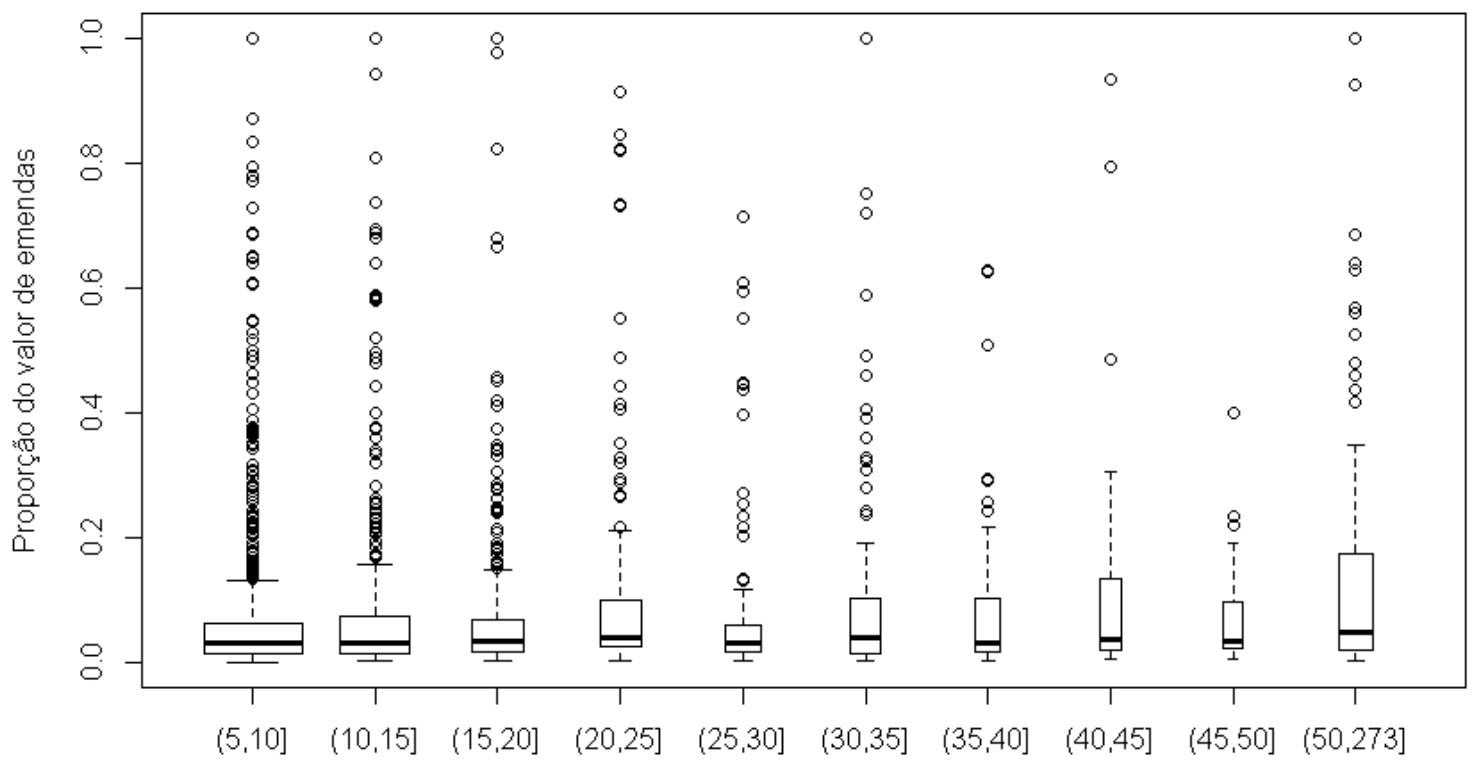

$\mathrm{QL}$ do candidato no municipio

O gráfico 6 mostra que o efeito é ainda mais sutil do que o verificado, quando observamos a simples distribuição de votos dos candidatos. A diferença entre as médias é mínima, a mediana nunca ultrapassa a marca de 0,05, e a variação é grande. A correlação de Pearson entre quociente locacional e proporção do valor das emendas é 0,14, e uma regressão simples entre as variáveis apresenta um coeficiente da ordem de $10^{-3}$ com $\mathrm{R}^{2}$ de 0,02 . Ou seja, constatamos que o quociente locacional tem uma relação fraca com a alocação de emendas.

Como não há ainda um consenso formado sobre quais seriam as melhores medidas para mensurar quais são as cidades mais importantes eleitoralmente para os candidatos e quais são as medidas de concentração mais apropriadas, propomos dois novos indicadores.

O primeiro deles mede a probabilidade de um eleitor do município " $m$ " votar no candidato " $\mathrm{c}$ " menos a probabilidade de um eleitor qualquer do estado votar no candidato "C". Quanto maior a probabilidade de o candidato "c" receber votos de um eleitor 
do município " $m$ " frente aos outros municípios, maior é o valor esperado das emendas nesse município. Isso porque seguimos tentando responder à pergunta sobre se os recursos provenientes das emendas individuais ao orçamento são usados para premiar os votos recebidos na eleição.

A fórmula para o cálculo do índice é a que se segue:

$$
\begin{gathered}
\text { Ind } 1=[P(C=c \mid M=m)-P(C=c)] \\
-P(C=c \mid M=m) \leq \text { Ind } 1 \leq 1-P(C=c) \\
P(C=c \mid M=m)=\frac{V_{i, m}}{V_{m}} \\
P(C=c)=\frac{V_{i}}{V_{t}}
\end{gathered}
$$

\section{Gráfico 7 - Proporção do valor das emendas (valor) por faixa do Indicador 1}

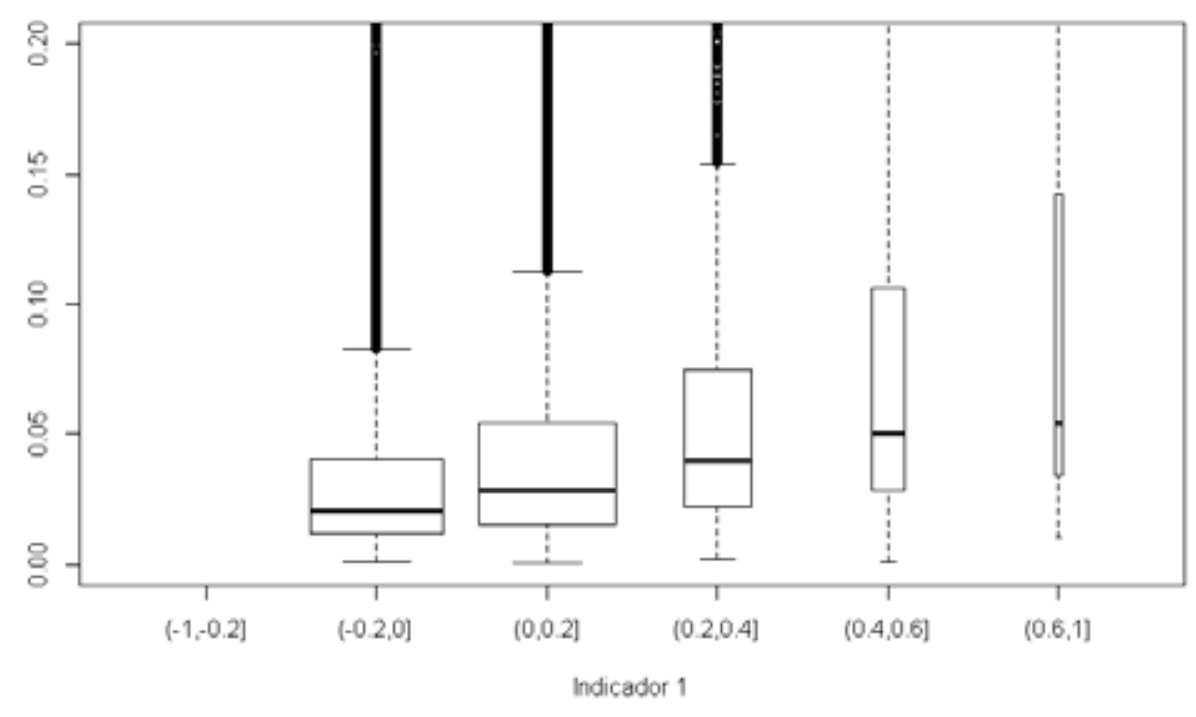

Resultados negativos indicam que a proporção de votos do candidato "c" no município " $m$ " foi menor do que sua proporção no estado como um todo. Ainda assim, observamos a alocação de emendas em municípios localizados nessa faixa, o que vai completamente de encontro com a hipótese do uso das emendas como meio de premiar os eleitores pelos votos dados ao candidato na última eleição. 
Mais uma vez observamos que a variação dos valores médios das emendas é mínima entre as faixas do indicador, e que os desvios são de tal ordem que tendem a anular qualquer efeito encontrado. O coeficiente de Pearson nesse caso é 0,14, e o coeficiente da regressão linear simples é 0,12 com $R^{2}$ de 0,02.

O segundo indicador proposto mensura a probabilidade de um eleitor do município " $m$ " votar no candidato " $c$ " dividida pela probabilidade de um eleitor de qualquer município exceto " $m$ " votar no candidato "c". Quanto maior o valor de indicador 2, maior é a proporção do valor esperado das emendas no município.

A fórmula para o cálculo do índice é a que se segue:

$$
\begin{gathered}
\text { Ind } 2 \equiv \frac{P(C=c \mid M=m)}{P(C=c \mid M \neq m)} \\
0 \leq \text { Ind } 2 \leq \infty \\
P(C=c \mid M=m)=\frac{V_{i, m}}{V_{m}} \\
P(C=c \mid M \neq m)=\frac{V_{i}-V_{i, m}}{V_{t}-V_{m}}
\end{gathered}
$$

Novamente, devido à limitação de espaço e à ausência de variação entre as legislaturas, optamos por apresentá-las todas reunidas em um único gráfico.

Gráfico 8 - Proporção de alocação das emendas (valor) por faixa do Indicador 2

Proporção do valor das emendas

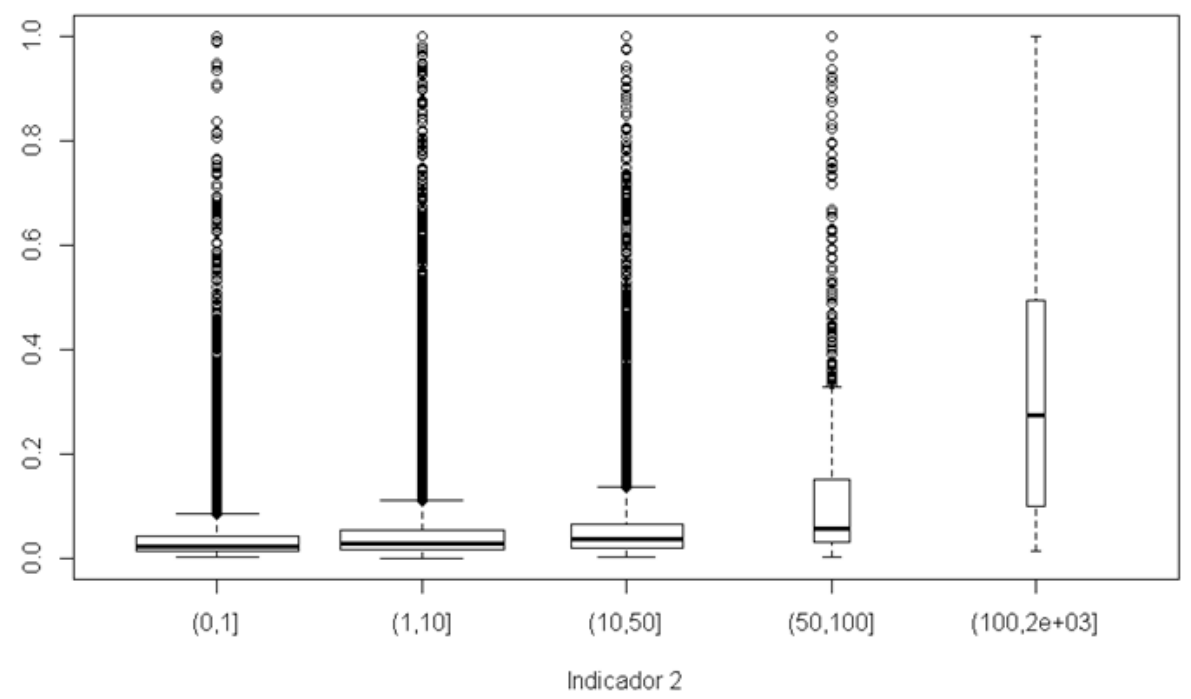


Embora se verifique uma tendência ao aumento do valor das emendas conforme aumenta o desempenho mensurado pelo indicador 2, tendência essa quase imperceptível entre as três primeiras faixas e mais evidente na última (que reúne uma pequena quantidade de casos), a grande oscilação dos valores não permite nenhuma afirmação contundente quanto ao movimento observado. Ainda assim, esse indicador é o que mais evidencia uma diferença na alocação das emendas pelos municípios onde o desempenho eleitoral dos deputados foi muito melhor do que nos demais. O coeficiente de Pearson entre as variáveis é de 0,22. A regressão linear simples apresenta coeficiente de 0,001 com $R^{2}$ de 0,05 .

\section{Considerações finais}

Este trabalho se propôs a explorar o universo das emendas individuais ao orçamento da União em busca de um suposto uso das mesmas como moeda de troca entre eleitores e eleitos, isto é, como meio de os deputados premiarem os eleitores que o apoiaram e permitiram o sucesso de sua empreitada eleitoral.

Já na primeira descrição dos dados, notamos que é pouco plausível que esse seja o uso principal dado às emendas pelos parlamentares, uma vez que as emendas que têm por destino um município específico perdem importância ao longo do tempo, e na última legislatura representam 30\% dos valores das emendas individuais. O restante tem como destino, principalmente, os estados, sem localização específica dentro do seu território.

Mesmo fazendo uso de diferentes indicadores para mensurar o "bom desempenho eleitoral" e os municípios importantes eleitoralmente para os deputados, não foi possível identificar uma correlação decisiva entre votos e emendas. Todos os indicadores testados seguem o mesmo padrão, há sempre uma pequena vantagem no valor das emendas para os municípios com melhor desempenho, todavia a variação é sempre muito grande. No caso do indicador mais direto de desempenho eleitoral (proporção de votos do candidato no município), encontramos uma correlação de Pearson mais elevada do que quando utilizados os demais indicadores. Mesmo neste caso, porém, não temos segurança quanto às implicações causais desta análise, já que características 
específicas dessa medida (por exemplo, o fato de ela encontrar-se por definição entre 0 e 1) podem inflar artificialmente o valor da correlação de Pearson.

Isso não significa que o bom desempenho eleitoral não pode ser um dos fatores que os deputados levam em conta na distribuição das suas emendas, mas ele não parece ser o mais relevante, com maior peso na tomada desta decisão. Por se tratar de um trabalho exploratório, entendemos que ainda há um caminho a ser percorrido antes que possamos afirmar de forma mais enfática se existe ou não relação entre desempenho eleitoral e alocação das emendas.

Como próximos passos para a continuidade dessa pesquisa, acreditamos ser necessário, seguindo sugestões de Silva (2009) e Barone (2014), investigar o peso dos prefeitos na alocação das emendas, além de testar outras estratégias de uso das emendas, por exemplo, não como meio de premiar votos passados mas sim de conquistar votos futuros (melhorar o desempenho). Analisar a distribuiç̧ão dos valores das emendas dado o tamanho dos munícipios, a variação do comportamento dos deputados por região ou magnitude dos distritos, bem como apreender a distinção entre o conteúdo das emendas que tem como destino uma cidade e as de abrangência estadual, dada a importância desse fenômeno, parece-nos ser o caminho natural e necessário a ser seguido.

Por fim, um desdobramento natural deste trabalho é o aprofundamento do debate sobre os indicadores de desempenho eleitoral, para além dos indicadores de concentração. O debate é importante, interessante, foi aberto por Silva e Davidian (2013) e pela sua importância nos estudos eleitorais merece ter continuidade.

\section{Referência bibliográfica}

AMES, B. Electoral Strategy under Open-List Proportional Representation. American Journal of Political Science, v. 39, n. 2, p. 406-433, 1ํmaio 1995.

Os entraves da democracia no Brasil. [s.l.] FGV Editora, 2003.

BARONE, L. S. Eleições, partidos e política orçamentária no Brasil: explorando os efeitos das eleições locais na política nacional. São Paulo: Fundação Getúlio Vargas - Escola de Administração de Empresas, 2014. 
CARREY, J.; SHUGART, M. Incentives to cultivate a personal vote. Electoral Studies, v. 14, p. 417439, 1995.

DINIZ, S. Interações entre os poderes Executivo e Legislativo no processo decisório: avaliando sucesso e fracasso presidencial. Dados, v. 48, n. 2, p. 333-369, jun. 2005.

FIGUEIREDO, A.; LIMONGI, F. Executivo e Legislativo na nova ordem constitucional. [s...] Editora FGV, 1999. . Incentivos eleitorais, partidos e política orçamentária. Dados, v. 45, n. 2, p. 303-344, jan. 2002.

Processo orçamentário e comportamento Legislativo: emendas individuais, apoio ao Executivo e programas de governo. Dados, v. 48, n. 4, p. 737-776, 2005.

Poder de agenda e políticas substantivas. In: MAGNA, I.; RENNÓ, LÚCIO (Eds.). Legislativo brasileiro em perspectiva comparada. [s.I.] UFMG, 2009. p. 77-104.

FREITAS, R. Poder de agenda e participação legislativa no Presidencialismo de coalizão brasileiro. [s.l.] Universidade de São Paulo, 2010.

LAMOUNIER, B. Estrutura institucional e governabilidade na década de 1990. In: REIS VELLOSO, J. P. DO (Ed.). O Brasil e as reformas políticas. [s.I.] José Olympio, 1992. .

MAINWARING, S. Políticos, partidos e sistemas eleitorais. Novos Estudos-CEBRAP, n. 29, 1991. MAYHEW, D. R. Congress: The Electoral Connection. [s.I.] Yale University Press, 1974.

MESQUITA, L. Emendas ao orçamento e conexão eleitoral na Câmara dos Deputados. [s.l.] Universidade de São Paulo, 2008a.

. Emendas ao orçamento e conexão eleitoral na Câmara dos Deputados. [s.l.] Universidade de São Paulo, 2008b.

PEREIRA, C.; MUELLER, B. Comportamento estratégico em Presidencialismo de coalizão: as relações entre Executivo e Legislativo na elaboração do orçamento brasileiro. Dados, v. 45, n. 2, p. 265-301, jan. 2002.

; RENNO, L. O que é que o reeleito tem? Dinâmicas político-institucionais locais e nacionais nas eleições de 1998 para a Câmara dos Deputados. Dados - Revista de Ciências Sociais, v. 44, n. 2, p. 133-172, 2001.

O que é que o reeleito tem? O retorno: o esboço de uma teoria da reeleição no Brasil. Revista de Economia Política, v. 27, n. 4, p. 664-683, dez. 2007.

SILVA, G. P. da. Uma discussão acerca das regras eleitorais do sistema político brasileiro e dos incentivos ao comportamento parlamentar. São Paulo: Fundação Getúlio Vargas Escola de Administração de Empresas, 2009. 
T\&P Lara Mesquita

Graziele Silotto

Joyce Luz

Paulo Hubert

; DAVIDIAN, A. Identification of Areas of Vote Concentration: Evidences from Brazil.

Brazilian Political Science Review, v. 7, no 2, 2013.

Recebido: 10/8/2014

Aceito: 6/11/2014 